\title{
Cuticle microstructure as a new tool in systematic paleontology
}

\author{
David A. Waugh \& Rodney M. Feldmann \\ Department of Geology, Kent State University, Kent, Ohio 44242, USA
}

Keywords: Decapoda, cuticle, microstructure, systematic paleontology

\begin{abstract}
Fossil decapod cuticle has received little systematic study. The purpose of the present note is to survey the cuticle architecture of eleven extant decapod crabs arrayed within ten families, and to develop a classification scheme of cuticle types suitable for describing fossil and Recent decapod cuticle morphology.
\end{abstract}

\section{Introduction}

Fossil decapod cuticle has received little systematic study; notable exceptions are Feldmann \& Tshudy (1987), Plotnick (1990), Briggs et al. (1998), Feldmann \& Gazdzicki (1998), Vega et al. (1998) and Haj \& Feldmann (2002). Thus, cuticle structure can be thought of as a dimension of fossil and extant arthropod morphology that has remained untapped. The purpose of the present note is to survey the cuticle architecture of eleven extant decapod crabs arrayed within ten families, and to develop a classification scheme of cuticle types suitable for describing fossil and Recent decapod cuticle morphology. The ultimate goal of understanding and using the microstructure of cuticle as a taxonomic character, especially at higher taxonomic levels, is to use cuticle to test and refine phylogenies of fossil decapous. Additionally, it might be possible to incorporate fragmentary fossil material into studies that previously have relied on specimens large enough to identify from traditional external characteristics, thereby helping to realize the true diversity of fossil decapod assemblages. Clearly, study of decapod cuticle is likely to be very helpful to many areas of paleontological research, even though the topic has, to date, received little attention.

\section{Cuticle and taxonomy}

Microstructure of skeletal elements provides a new dimension to the interpretation of fossil material previously described only in a macro-morphological manner. Recent work with brachiopods and bivalves has successfully used microstructure to solve taxonomic problems (Schneider \& Carter 2001; Tschudin 2001; Williams \& Holmer, 2002). Initial examination of decapod cuticle microstructure has shown considerable variation that has important implications for systematic paleontology (Waugh \& Feldmann 2002, work under way) (Fig. 1.).

Taxonomy of fossil decapods is based largely on the morphologic features of the dorsal carapace because of its high preservation potential. Important linkages have been made between 'hard' and 'soft-part' morphology, helping reconcile different classification schemes proposed by decapod systematists working with extant and fossil material (Schweitzer \& Feldmann 2000; Schweitzer, 2003). This work shows that certain "hard parts" may be used as proxies for taxonomy based on "softpart' morphology. Cuticle morphology may help to further bridge the gaps between classifications based on extant and fossil material. Cuticle microstructure is often preserved and has been recognized in arthropod material as old as Cambrian (Dalingwater et al., 1991). Observation of fossil 

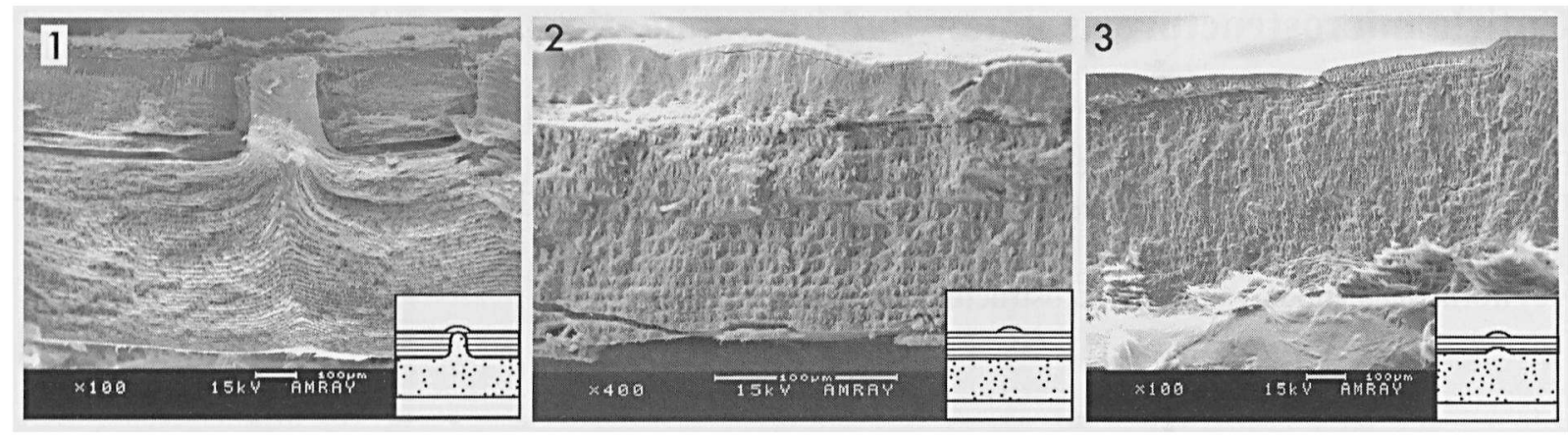

Fig. 1. Scanning electron micrographs (1-3) and interpretative sketches to show variation in the formation of bumps or nodes on the cuticle surface; 1 - involvement of epi-, exo-, and endocuticle, with a pronounced node in the endocuticle; 2 - involvement of epi-, and exocuticle only; 3 - involvement of all three cuticle layers to produce a low node.

material shows that many of the cuticular characters are preserved (Feldmann \& Gázdzicki, 1998; Haj \& Feldmann, 2002). By developing a new system of classifying structures within cuticle, an entirely new set of characters can be incorporated into systematics.

To date, studies have not described cuticle in a manner permitting direct comparison. The present study is the first step in addressing this issue. The term analytical is used in the sense of Hageman et al. (1998), in that the cuticle has been subdivided into its component parts for classification. This classification, based on specific character states for features identified in cuticle, will allow for more comprehensive comparison of cuticle across and within taxa. It must be noted that this is a classification of cuticle morphology, not a phylogenetic classification. Furthermore, the samples used in this study, although diverse, are not sufficient to permit drawing final taxonomic conclusions. The outcome of this work is a preliminary classification scheme for cuticle morphology; it is neither a comprehensive cuticle study, nor a phylogenetic classification of the Decapoda.

Classes of character traits identified in extant material and used in the Analytical Cuticle Classification Scheme include: surface ornament (less than $1 \mathrm{~mm}$ ), internal morphology of tubercles, calcification style, and nature of the outermost layer of the cuticle (epicuticle) (Waugh \& Feldmann, 2002). More classes of characters exist but have not been fully developed into usable character states. Character states in each class will be expanded as more material is studied. There are caveats, however. The molting cycle complicates the observation of cuticle microstructure. Cuticle may vary spatially on an individual, and it may also vary with instar and within each instar. This variation has not yet been examined.

\section{Conclusion}

Variation in cuticular construction and architecture is much greater than previously thought. Cuticle structure cannot be adequately compared across large numbers of taxa without a system of classification that can be coded numerically. The analytical classification scheme presented here will make such comparisons possible.

\section{References}

Briggs DEG, Bierstedt A, Evershed RP, Meischner D, Stankiewicz BA. 1998. Taphonomy of arthropod cuticles from Pliocene lake sediments, Willershausen, Germany. Palaios 13: 386-394.

Dalingwater JE, Hutchinson SJ, Mutvei H \& Siveter DJ. 1991. Cuticular ultrastructure of the trilobite Ellipsocephalus polytomus from the Middle Cambrian of Öland, Sweden. Palaeontology 34: 205-217.

Feldmann RM, Gazdzicki A. 1998. Cuticular ultrastructure of fossil and living homolodromiid crabs (Decapoda:Brachyura). Acta palaeont. pol. 43: 1-19.

Feldmann RM, Tshudy D. 1987. Ultrastructure in cuticle from Hoploparia stokesi (Decapoda: Nephropidae) from the Lopez de Bertodano Formation (Late Cretaceous-Paleocene) of Seymour Island, Antarctica. Jour. Paleo. 61: 1194-1203. 
Hageman SJ. Bock PE, Bone Y, McGowan B. 1998. Bryozoan growth habits: classification and analysis. Jour. Paleo. 72: $418-436$.

Haj A, Feldmann RM. 2002. Functional morphology and taxonomic significance of a novel cuticular structure in Cretaceous raninid crabs (Decapoda: Brachyura: Raninidae). Jour, Paleo. 76: 427-485.

Plotnick RE. 1990. Paleobiology of the arthropod cuticle. In: Mikulic DG. (ed.). Arthropod paleobiology: 177-196. Lawrence: Paleontological Society.

Schneider JA, Carter JG. 2001. Evolution and phylogenetic significance of cardioidean shell microstructure (Mollusca, Bivalvia), Jour. Paleo, 75: 607-643.

Schweitzer CE, Feldmann RM. 2000. New species of calappid crabs from western North America and reconsideration of the Calappidae sensu lato. Jour. Paleo. 74: 230-46.
Tschudin PE. 2001. Shell morphology, shell texture and species discrimination of Caribbean Tucetona (Bivalvia, Glycymeridae), Jour, Paleo. 75: 658-679.

Vega FJ, Davila V, Lehman T. 1998. Cuticle structure and taphonomy of Dakoticancer australis Rathbun; paleoecological implications for a Late Cretaceous shore in Northeast Mexico. Geol. Soc. Am., Abstr. Progr. 30: 34.

Waugh DA, Feldmann RM. 2002. Analytical description of decapod cuticle microstructure: Integration of cuticle morphology into classification. Geol. Soc. Am., Abstr. Progr. 34: 358.

Williams A, Holmer LE. 2002. Shell structure and inferred growth, function and affinities of the sclerites of the problematic Micrina. Palaeontology 45: 854-873.

Received: 12 March 2003 